\title{
A Study on the Cultivation of College Students' Self-leadership Based on Subject Competitions
}

\author{
Shujuan Yu \\ Zhejiang University of Water Resources and Electric Power, Hangzhou China \\ yushujuan2009@sina.com
}

Keywords: subject competitions; self-control; self-leadership; college students

\begin{abstract}
Based on theoretical teaching, the subject competitions train students' logical thinking ability and independent problem-solving ability in the form of competitions. The subject competitions are characterized by openness and voluntariness, students' subjectivity, collaboration, inheritance and competitiveness. They not only can train the intelligence and will of college students, but also are an effective carrier for the cultivation of the college students' self-leadership. Owing to the characteristics of the subject competitions, they can stimulate students to challenge themselves and enhance their will, play an active role and provide students with a platform for independent learning and communication. The specific training mode is to focus on competition projects, take their content as objects for learning and research, and organize and train students to acquire self-learning, self-control and self-organization in the process of participation, so as to achieve the purpose of training students’ leadership.
\end{abstract}

\section{Introduction}

Thoresen and Mahoney (1974) proposed the concept of self-control for the first time. They defined it as an ability to control himself when there is no external constraints. The self-control theory holds that human beings have the talent of self-consciousness, and everyone can influence their self-cognition and motivation so that they can manage their own behaviors. With the rise of the knowledge economy, employees have higher education, ability and quality, and they have gradually participated in relevant decision-making in cooperation. In 1978, Steven Kerr and Jemier first presented their concept of alternative leadership. In 1980, Manz and Sims proposed the concept of self-management on the basis of former researches, and since then opened up the research path of self-leadership theory. As a special form of self-impact and self-control, self-leadership is a process of the individual's active application of self-cognition, mental model, and behavioral model to regulate, manage and integrate his own thinking, emotions, behaviors and circumstances. The university campus is a place that emphasizes independence and focuses on self-establishment. College students also have the desire to shape their own image and design themselves. As students pay attention to the development of self-worth and the awareness of open competition increases, students have a strong desire for knowledge and a strong ability to learn. So they need such a platform as subject competitions to show themselves. In this process, self-leadership training can better guide the development of college students' professional abilities and improve their overall quality, social competitiveness, group performance and innovation awareness.

\section{Characteristics of subject competitions}

Subject competitions refer to training people's intelligence and will, and students' logical thinking ability and independent problem-solving skill through competitions. Closely combined with theoretical teaching, they are effective means and important carriers to help students learn to think independently and cultivate their innovation awareness, team spirit and practical abilities, and also are effective ways to cultivate students' self-control and self-leadership abilities. They have the following features: 
1) Openness and voluntariness. As a carrier, the subject competitions make the students with different majors but common interests and pursuits voluntarily gather. The college students are full of passion and initiative in exploring the unknown world, especially in activities that they are interested in and those with certain challenges. With spontaneous organization and participation, students tend to have stronger motivation to enhance their abilities.

2) Students' subjectivity. Many competitions in colleges and universities are based on the application of knowledge in different disciplines. Some competitions need to be completed by the joint efforts of students across majors and disciplines. It requires the abilities of self-learning, self-challenge, and self-management. Students who want to participate in such activities are willing to spend their spare time in learning more knowledge.

3) Collaboration. The competitions teams participate in depend on the mutual cooperation and support of the members, so teamwork, communication and exchange, brainstorm, and mutual help are particularly important. Collaborative learning should be a characteristic a group or team-type contests must have, and a way of study for members who need to complete the task together. In order to achieve a common purpose or goal, members need to research and study together regularly.

4) Inheritance. Passing on experience is a major feature of the competitions. This approach has greatly improved the learning efficiency of new members. Passing on experience is that old players guide new players to learn while doing, forming a flexible team culture of subject competitions, and providing sufficient candidates and motivation for the long-term mechanism of the subject competitions.

5) Competitiveness. Multiple selections are often carried out within the school if students want to participate in national or provincial subject competitions. This elimination mechanism effectively stimulates the sense of competition among the players and brings a demonstration effect.

\section{Advantages that subject competitions cultivate students' self-leadership}

Self-leadership is a behavioral ability of self-assessment and self-impact, as well as a positive behavioral process in which people improve their overall performance through self-direction and self-motivation. The subject competitions have great advantages in cultivating students' innovation ability, comprehensive ability and independent leadership ability.

\subsection{Inspiring students' engagement}

Students' engagement is also an aspect that affects self-leadership. The ways in which students exercise their leadership during colleges are mainly running for class committees, student unions, various clubs and organizations or self-employment, which can only absorb some outstanding students, while others who fail to run for those can participate in the competition to exercise their leadership. The competition organization is another platform to absorb students who have ideas to exercise and improve their abilities. Students participating in these activities have strong abilities, demand more of themselves, and have the will to improve their own leadership. To this end, it is necessary to actively absorb students who have not held positions in the classes and clubs and provide them with a platform for self-motivation and self-control training.

\subsection{Providing autonomous learning platform}

Self-leadership includes self-management, self-monitoring, self-observation and self-motivation, confident optimism, strong willpower, self-decision making, and interpersonal skills. Different from the study of the curriculum, the subject competitions based on its own characteristics require students to complete the task in their spare time through self-learning and self-training organized by themselves. Although collaborative learning is a part of the competitions, the main purpose is to develop students' abilities of self-knowledge, self-management, and self-government in accordance with student-centered philosophy. Teachers can offer guidance in the way of collaborative learning in this process, and assess and motivate them in a performance-based manner so as to enhance students' self-leadership. 


\section{How to train the ability of self-leadership in subject competitions}

First of all, related competition organizations need to be established and student-oriented activities need to be conducted. For the competitions students must participate in each year, competition clubs need to be set up to comply with students' willingness to participate in challenging activities. When new students will be recruited every year, the competition clubs will organize activities of taking in new members, and students with willingness and ideas will be organized to study and improve the relevant knowledge of competitions. Learning activities are divided into three categories, and the first is pre-match training activities. Prior to the competitions, students' participation in the collaborative learning is also an aspect that influences self-leadership. The team leader is recommended by students. Old members usually pass their experience to new members and are responsible for the training of the competitions-related content and the organization of the training and learning of the latter. The second is the self-exercise competitions. After new members have mastered the relevant content, the team will organize competitions among the internal members. During the event, old members must learn to plan, organize and control the activities. Two or three matches must be organized each semester. The third is the off-campus leagues. Students will contact the same-type clubs outside the school to conduct inter-school competitions. During this process, students' external communication, interpersonal communication and coordinate ability will be trained.

Besides, let students organize regular competitions' knowledge exchange sessions by themselves. For students from different majors, they gather together because of their interests, and each kind of competition requires a certain amount of theoretical knowledge. So students need to strengthen their theoretical literacy, and even have to learn some knowledge beyond their own majors. This requires students to regularly organize training and exchanges. During this process students in the competition club can not only improve their professional qualities, but also improve their self-leadership.

What's more, competition players' selection mechanism allows students to experience the spiritual rewards for learning. Self-targeting is an important dimension of the behavioral focusing strategies in Manz's self-leadership theory. Students who want to participate in national or provincial competitions must work harder than others to constantly modify and improve their manuscripts or programs. This requires to help those students who are strongly motivated to participate in national or provincial competitions to pay their attention to the achievement of goals. Before competitions, teachers encourage students to think more and practice more. These students should be trained to learn to arrange training by themselves. Both new and old players must promote management of their own behaviors through self-consciousness. The success or failure of each competition will make students adjust, manage and integrate their thinking, emotions, behaviors and circumstances. After competitions, many students summarize that except for classroom learning they spend the rest of the time on training every day. When they encounter bottlenecks, they are sometimes very annoyed. At that time, they need self-adjustment, self-encouragement, and mutual motivation.

\section{Conclusion}

The subject competitions are another platform for cultivating students' self-leadership, whose model is flexible. After years of practice, it has achieved very good results. In this process, learning and training, self-organization, self-management, and self-motivation related to competition activities should be carried out with student-centered philosophy as their core. Schools should create a good campus culture atmosphere for students, encourage more students to participate in academic competition activities, so that they can put their theoretical knowledge into practice, and be able to truly apply what they have learned. This is a practice and test for students' self-leadership as well as an invisible force to promote students' development. 


\section{References}

[1] Cao Weilin,Chen Yuanyong,Guo Jiangping. Analysis of Research Frontiers of Self-leadership and Prospects of Future Hotspots. Foreign Economic Research.2009 (7):61-64

[2] Zhao Conghuan, Zhou Zuoyu. Education for Self-leadership of College Students. College Education Science. 2017 (2): 99-102

[3] Yang Tingqi, Ling Wenzhao, Jiang Hong. Research Status of Self-management theory-Based on the Perspective of Organizational Behaviors. Science and technology Management Research. 2009 (6): 560-563

[4] Chen Zhengqin, Wu Tao. College Students' Entrepreneurship Education and Development of Self-leadership. Exploration and Contend. 2013 (12): 106-109

[5] Liu Li, Yang Xiaohua. Constructing the "Integration of Competition and Learning” Ecosphere to Lead the Cultivation of Creative Talents in Universities, Experimental Technology and Management. 2016(6) 34:18-21

[6] Li Guofeng, Zhang Shiying, Li Bin. A Study on the Cultivation Model of College Students' Innovative Ability Based on Subject Competitions. Experimental Technology and Management. 2013(3):24-26 